\title{
Reflective Practice: A Tool for Enhanching Quality Assurance in Science Education at Nigerian Colleges of Education
}

\author{
Aminat Aderonke Agoro \\ Department Of Integrated Science \\ Emmanuel Alayande College Of Education, Oyo \\ Oyo State, Nigeria \\ E-mail address:ronkeagoro@yahoo.com
}

Doi:10.5901/jesr.2013.v3n7p205

\begin{abstract}
This paper illustrates how reflective practice can be used as a tool to enhance quality assurance control in science education at tertiary level. It examines what quality assurance and reflective practice/teaching are, the approaches of reflective practice and how to be a reflective teacher as well as benefit that can be derived from being a reflective teacher. It further concludes that if experience, inexperience and pre-service teachers are given the chance to reflect continuously before, during and after a class, reflection can be turned to a habit which will encourage professional development as well as enhancing quality assurance in teaching and learning process.
\end{abstract}

Keywords: Quality Assurance, Science Education, Reflective Teaching, Reflective Practice.

\section{Introduction}

Quality assurance in teaching and learning in tertiary institution is currently of major concern all over the world. The fiscal constraints faced by many countries, coupled with increasing demand has led to overcrowding, deteriorating infrastructure, lack of resources for non-salary expenditures such as textbooks and laboratory equipment, and a decline in the quality of teaching and research activities. Harvey and Green (1993) distinguish three definitions of quality that are relevant to the issue of quality assurance (QA): as value for money, as fit for the espoused purpose, and as transforming. This implies that the definition one gives to it depends on the kind of quality to be assured. The last two sees QA as maintaining and enhancing the quality of teaching and learning in the tertiary institution. QA is concerned with assuring that teaching and learning does now, and in future will continue, to fit the purpose of the institution.

Quality Assurance is not concerned with quantifying aspects of the system, but with reviewing how well the whole institution works in achieving its mission, and how it may be improved. This is analogous to what an individual reflective practitioner does (Schon 1983). A quality institution is one that has high level aims that it intends to meet, that teaches accordingly, and that continually upgrades its practice in order to adapt to changing conditions, within resource limitations Reflective practice was introduced by Donald Schon in his book: The reflective practitioner in 1983. However, the concepts underlying reflective practice are much older. It focuses on the ways people think about their experiences and formulate responses as the experiences happen. This approach makes a clear distinction between "thinking on action" and "thinking in action". Thinking on action is the way of analyzing experiences as they happen while thinking in action determines how responses are formulated (Krause, 2004). This whole idea is considered as "thinking on your feet". Reflective practice leads to reflective teaching.

Reflective teaching means looking at what you do in the classroom, thinking about why you do it, and thinking about if it works or not. Reflection, according to Clarke (2007), refers to thinking about the actual teaching which involves the thought teachers have before, during and after a lesson. It is a process 'of self -observation and self-evaluation. Selfevaluation and inquiry into one's own practice is important for teachers especially in the developing countries like Nigeria. Where books are not available, and the available ones are beyond the reach of most citizen, in-service training for teacher are rare, teacher overworked and underpaid, large pre-service teacher ratio to the lecturer, little or no assess to professional benefit, inadequate material resources, inadequate lecture room e.t.c. The only transformation tool in enhancing quality assurance is reflective practice.

Griffiths and Tam (1992) in Problete (1999) categorised reflection into into two: reflection -in -action and reflection 
-on -action. Reflection -in -action refers to what happens when ones is presented with novel puzzles, the resolving of these puzzles in the contex of action, according to Schon (1983) unites means and ends, research and practice, and know and doing. This type of reflection is personal and private. It occurs as an action is going on and the reaction is rapid i.e act and react. Reflection - on -action on the other hand is seen as a procedure for studying immediate, at-hand events in order to understand them and develop a conceptual framework for useful practice. It involves recalling one's teaching after the class. This is interpersonal and occurs after an event might have taken place. Reflection on action includes:

- Involvement in a scenario (an action);

- Recording of the scenario (for getting stable idea);

- Determinations, interpretations and evaluation;

- Formation of educational construal; and

- Confirmation to determining whether the construal has meaning to other practitioner Garman (1989) in Problete (1999).

Another type of reflection is reflection -for- action which occurs before an event is taken place. All is embedded under reflective practice

Reflective teaching is a means of professional development which begins in our classroom. It is paying critical attention to the practical values and theories which inform everyday action, by examining practice reflectively and reflexively (Bolton, 2010). Dewey (1933) in his concept of "reflective inquiry" viewed the students as an inquirer and an active participant in learning. He assumed that the interaction of subject-matters and method of inquiry could not be ignored in schooling. Following this line of thinking, the reflective teacher makes decision based on a problem-solving paradigm (Orlich, Harder, Callahn, Travisan \& Brown, 2010). Problems are not viewed as obstacles to overcome but as opportunities to be met. Teachers reflect on problems, and as part of a learning community, they call on others (i.e. their peer and senior colleagues) to reflect on identified problems. In such cases, they collectively list a series of alternatives that they can take. Ultimately, such list is narrowed down to a set of actions that are ethical, just and educationally sound. Reflective teaching can be thought about in terms of asking searching questions about experience and conceptualized as both a state of mind and an on-going type of behavior. Being a reflective practitioner at any stage in teacher development involves constant, critical look at teaching and learning and at the work of the teacher (Harrison, 2009). Reflective Teaching deals with active research, critical thinking and professional enquiry. It also deals with thinking deeply to solve a given problem and in doing this you ask a lot of thought provoking questions like: why do I teach the way I do? What principle underlining my teaching? Should I do it differently? What are the major problems that I face in my teaching? Why does a particular method work for student A or topic A but not for student B or topic B? What are my doing right or wrong in my classrooms? What made my lesson seem so successful/not successful?

\section{Models of Reflective Practice}

There are several models of reflection used to draw lesson some of which are presented below:

\subsection{Argyris and Schon Model of Reflective Teaching}

Argyris and Schon pioneered the idea of single loop and double loop learning in 1978. The theory was building around the recognition and amendment of a perceived fault or error. Single loop learning is when a practitioner, even after an error has occurred and a correction is made, continues to rely on current strategies or technique when a situation again comes to light. Double loop learning involves the modification of personal objectives, strategies or policies so that when a similar situation arises a new framing system is employed (Argyris \& Schon, 1978)

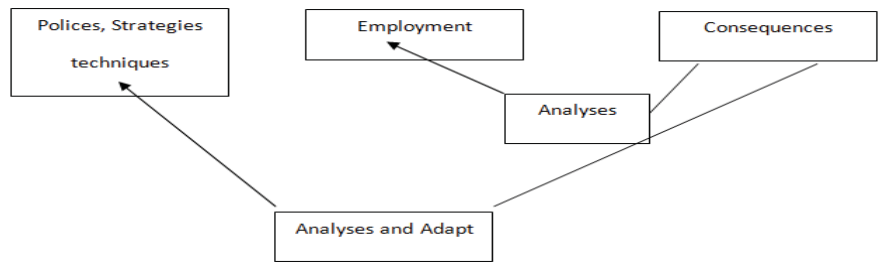

Fig.1. Adaptation of the Argyris and Schon Double loop Learning Model 
Schon himself introduced some years later the concept of Reflection-in-action and Reflection-on-action the summary of which was presented in the figure below:

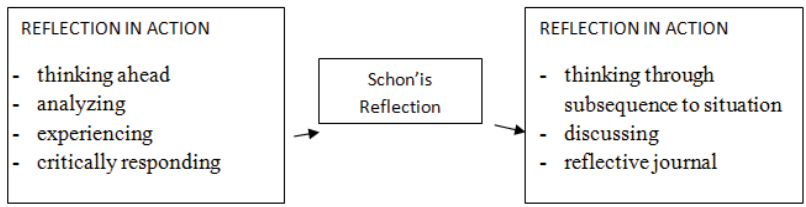

Fig. 2. Schon concept of reflection-in-action and Reflection-on-action

\subsection{Kolbs' Reflective Model.}

It highlights the concept of experimental learning and is centered on the transformation of information into knowledge. This takes place after the situation has occurred and entails a practitioner reflecting on the experience, gaining a general understanding of the concepts encountered during the experience and then testing these general understandings on a new situation. In this way the knowledge that is gained from a situation is continuously applied and reapplied building on a practitioner's prior experience and knowledge (Kolb \&Kolb, 2005).

Figure 3. Kolbs' reflective model

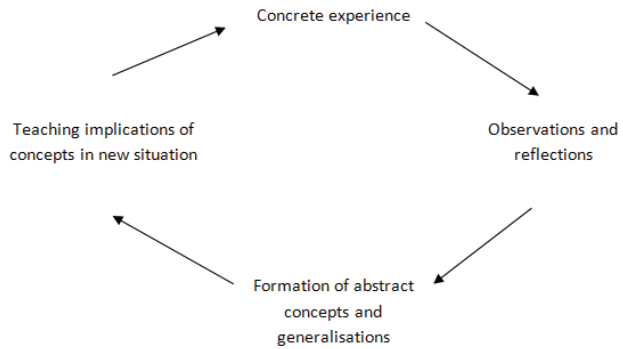

Source: Kolb, 1984 in Kolb and Kolb, 2005

Reflective practice occurs at all stages of the teaching process, planning, action (execution), and evaluation (Clark, 2007). That is, the thinking about teaching, which involves the thoughts teachers have before, during, and after the actual enactment of a lesson. This construct is parallel to the thinking processes identified by Polya (1945). In his concept of mathematical problem solving, there are three phases: (a) Understanding, (b) Planning, and (c) Looking back.

According to Clarke (2007), teachers should engage in similar types of thinking before they teach a lesson. To achieve desired results, teachers should reflect on their teaching goals and method and how these interface with the demographics and abilities of their students. This process would allow them to clarify their knowledge base, the content, and their students' learning styles and to crystallize the pedagogy to be implemented (Clark, 2007). Teachers must consider the challenges that students may encounter and strategies to assist students in overcoming them. Polya's "looking back" phase is the reflective thinking that teachers engage in after they teach a lesson (Artzt \&Armour-Thomas, 2002). At the end of the lessons, teachers evaluate the lesson goals and the actions of both themselves and their students as well as define the points at which difficulties emerged. They must consider the strategies employed and when necessary make modifications. The self-assessment helps identify what was not addressed and the unexpected challenged of the lesson. Failure to acknowledge these challenges could impede teachers' self-improvement and their students' achievement (Harrison, 2008).

\subsection{Methods of Reflection}

This includes the following:

- Reflective journal

- Videotaped lesson / peer conference 
- Students input and lesson evaluations

- Student can provide structural evaluations of a lesson

\section{Characteristics of a Reflective Teacher}

Orlich, et al (2010) lists the following as characteristic of a reflective teacher:

- Cares about students

- Understands the social context of schooling

- Questions assumptions

- Knows content

- Identifies Problems or issues

- Collects relevant data

- Constructs a plan of operation

- Uses many instructional strategies

- Practices problem-solving strategies

- Thinks prospectively and retrospectively

- Realizes that reflection is cyclical

- Evaluates the results and process used.

\section{Approaches to the use of Reflective Teaching}

Reflective practice occurs at all stages of the teaching process, in planning, action (execution) and in evaluation.

Leitch and Day (2000) submitted that the appeal of the use of reflective teaching by teachers is that as teaching and learning is complex, and there is not one right approach, reflecting on different versions of teaching, and reshaping past and current experiences will lead to improvement in teaching. As Larrivee, (2000) argues, Reflective practice moves teachers from their knowledge base of distinct skills to a stage in their careers where they are able to modify their skills to suit specific contexts and situations, and eventually to invent new strategies. In implementing a process of reflective practice teachers will be able to move themselves, and their schools, beyond existing theories in practice (Leitch \&Day, 2000).

Some reflective question that teacher can ask himself /colleague about a lesson include:

- What did you set to teach?

- Where you be able to accomplish the set goal?

- What teaching materials did you use? Were they effective?

- What strategy(ies) did you use? Were they effective?

- What kind of interaction occurred?

- Did you have any problem?

- Did you do anything different than usual during the lesson?

- Did you follow your lesson plan or you deviate from it?

- Were your students really challenged?

- What aspect did they like most about the lesson?

- What would you do differently if given a second chance to do that same class?

Before a lesson teacher can also do a self reflection by asking questions like:

- What are my greatest strength and weakness as a teacher?

- What is the biggest problem that am facing in my teaching (e.g. materials, class size, unresponsive student, lack of good communication among fellow teachers)?

- Reflect on a recent lesson, what worked well and why? What did not work well and why?

- Is your class student centered? Do you encourage learner autonomy? How?

\section{Benefit of Reflective Teaching}

The following are the advantages to be derived from using reflective teaching in classroom:

- It develops the quality of teaching through continuous improvements. 
- It gives educators new opportunities to reflect on and assess their teaching.

- It enables teachers to explore and test new ideas, methods, approaches, and materials.

- It provides opportunity to assess how effective the new approaches were.

- Teachers share feedback with fellow team members.

- They make decisions about which new approaches to include in the school's curriculum, instruction, and assessment plans.

- It significantly increases student motivation for learning

- It recognises individual progress

- It enhance and develop forms of collaborative learning

- It increase learner independence

- It enhance confidence Donald, (1985)

\section{Conclusion}

The paper has established that the Reflective teaching is effective at enhancing quality assurance in teaching and learning process. Building it into daily routine is a realistic way. It can be in form of jotting notes on daily lesson plan, keeping a teacher's journal or scheduling a weekly review over drinks with colleague, mentoring by senior colleagues. Consistent reflection will bring to light issues that need attention and provide opportunity for brainstorming with colleague for possible solution. It also bridges the gap between the micro and macro dimensions of teaching. Its use in teaching is a must and it is a necessary tool for effective and efficient science teaching in Nigeria. It is hoped that the experience shared in this paper will stimulate thoughts about the value of reflection on the STM teachers.

\section{References}

Argyris, C. A. and Schon, D. 1978. Organization Learning: A theory of Action perspective, Reading, Mass: Aderson Wesley

Artzt, A. F. and Armour - Thomas, E. 2002. Becoming a reflective mathematics teacher, A guide for observations and self-assessment. N. J. Lawrence Erlbaum Associates

Biggs John, 2001. The Reflective Institution: Assuring and enhancing the quality of teaching and learning. Higher Education 41: 221238.

Bolton, G. (2010). Reflective practice: writing and professional development. London: Sage.

Clarke, C. 2007. Reflective Teaching Model: A Tool for motivation, collaboration, self-reflection and Innovation in Learning. Georgia State University.

Dewey, J. 1933. How We Think: A Restatement of the relation of Reflection Thinking to the Educative Process. Chicago: Henry Regnery.

Donald R. Cruickshank, 1985. Uses and Benefits of Reflective Teaching. The Phi Delta Kappan. vol. 66 (10), pp. 704-706.

Harrson, 2009. Professional Development and the reflective Practitioner in Reflective Teaching and learning Edited by Sul Dymoke and Jennifer Hanson. SAGE publication London.

Harvey, L. and Green, D. (1993). 'Defining quality', Assessment and Evaluation in HigherEducation 18, 8-35.

Karause, K. L. 2004. Reflective teaching, Educational Psychology for learning and Teaching, 13, 1-44, Nelson Australia press Itd.

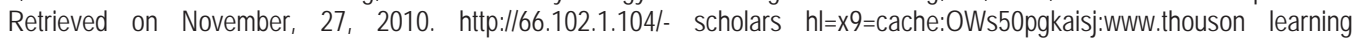
.com.au/higher/-education/krauwe/media/krause- chapter-13.pdftrekated:owsso pgkaisJ:scholar.google.com

Kolb, A. Y, Kolb, D. A. 2005. Learning style and Learning speaker, enhancing experimental Learning in higher education. Interactive learning environments, 18, pp. 245-261

Larrivee, B. 2000. Transforming Teaching Practice: Becoming the critical reflective teacher: Reflective Practice, vol. 1: 3, pp 293-307

Latch, R. and Day, C, 2000. Action Research and Reflective Practice: towards a holistic view' Educational Action Research, vol. 8:1 pp. $179-193$.

Orlich, D. C Harder, R. J., Callahan, R. C, Travisan, M. S and Brown, A. H. 2010. Teaching strategies. A guide to Effective instruction. Ninth Edition Wads worth CEN GAGE learning U.S.A

Poblete, D. Sr. 1999. A Reflective Teaching Model: An Adventist Assessment. 24th International Faith and Learning Seminar Held at Andrews University, Berrien Springs, Michigan, U.S A. June 20=July2, 1999

Polya, G. 1945. How to solve it? Garden City, NJ: Doubleday.

Schon D.A. 1983. The Reflective Practitioner, How Professionals Think in Action, Basic Books. New York

school children. Journal of Applied behaviour Analysis 19, 93-98. 